\title{
The reliability of patients' judgements of care in general practice: how many questions and patients are needed?
}

\author{
Michel Wensing, Cees van de Vleuten, Richard Grol, Albert Felling
}

Centre for Quality of Care Research, University of Nijmegen and University of Maastricht Michel Wensing, research fellow

Richard Grol, professor in general practice

\section{Department of Educational Development and Research, University of Maastricht Cees van de Vleuten, professor in education}

Department of Methodology,

University of Nijmegen Albert Felling, professor in research methodology

Correspondence to:

Dr M Wensing, Centre for Quality of Care Research, Quality of Care Research, University of Nijmegen, $9101,6500 \mathrm{HB}$ Nijmegen, The Netherlands.
Nox $9101,6500 \mathrm{HB}$

Accepted for publication 17 March 1997

\begin{abstract}
Objectives-To estimate the number of questions and patients that are needed to achieve reliable measurements of patients' judgements of care in general practice.

Design-Sensitivity study, using generalisibility theory and real data from surveys of patients.
\end{abstract}

Subjects-739 patients with chronic illness from 23 general practitioners in The Netherlands.

Main measures-The reliability coefficients of scores per patient and scores per general practitioner for patients' judgements of nine dimensions of care in general practice.

Results-For most dimensions the reliability per patient was 0.80 or higher if three questions were used, but for the evaluation of the "organisation of appointments" and "premises" five questions had to be used. To reach a reliability coefficient of 0.80 per general practitioner three questions and 90 patients, or five questions and 60 patients, were needed for most dimensions. Even more patients or questions were needed for the dimensions "availability for emergencies", premises, and "continuity". A reliability of 0.70 per general practitioner could be achieved if three questions and 60 patients were used, except for availability for emergencies and premises, for which more patients or questions were required.

Conclusions-Surveys of patients can only provide reliable information if the samples of questions and patients are large enough. It is important to distinguish between the reliability of scores per patient and the reliability per care provider, as well as between different dimensions of care. The reliability per patient is good for most dimensions if three questions are used, but a good reliability per care provider requires more questions or patients.

(Quality in Health Care 1997;6:80-85)

Keywords: patient satisfaction; questionnaires; reliability

\section{Introduction}

Research into patients' satisfaction has been stimulated by the rise of medical audit and quality assurance in health care in the past decade. Surveys of patients are regarded as an important means for involving patients' perspectives in the assessment and improvement of care delivery. In this context the results of the surveys are used to assess the quality of care delivered by a specific care provider or practice and to provide feedback to care providers who are supposed to change practice routines in response to this feedback. In such cases it is very important that patients' judgements of care have been shown to be valid and reliable.

In medical audit the opinions of individual patients, expressed as responses to questions, are aggregated per care provider. Aggregated scores - such as the percentage of patients that are satisfied-are treated as characteristics of the care provider. This has important consequences. The care provider is now the object of measurement or unit of analysis, not the individual patient: the conclusions refer to care providers, not to patients. This implies that the reliability of scores per patient is not crucial here, but the reliability of the aggregated scores. ${ }^{12}$ The problem of the level of analysis has hardly been considered in research into patients' satisfaction. An analysis of 40 studies on patients' satisfaction in primary care ${ }^{3}$ showed that most reported the reliability of the answers of individual patients. Only in three studies was the accuracy of aggregated scores given, whereas in 10 studies reliability coefficients related to individual scores were given. In the remaining 27 studies no information at all was given on the reliability or accuracy.

The reliability of the aggregated score depends on the number of questions in the questionnaire and on the number of patients that responded in the survey. The more questions and patients, the more reliable the measurement will be. For reasons of efficiency no more questions and patients should be used than are needed to achieve reliable measurements. On the other hand, too few questions or patients could lead to unreliable information. Unfortunately, insight into the number of questions and patients that are needed to achieve a reliable aggregated score per care provider is limited. In a study on patients' ratings of residents' humanistic qualities it was found that for a reliability coefficient of 0.80 per resident 50 patients are needed who should each answer 50 questions. ${ }^{4}$ A limitation of this study was that these predictions were based on two patients per physician. 
The reliability of scores from a measurement can be expressed as the consistency of the attained scores when the measurement is repeated. As it is often difficult to repeat measurements, in many situations one measurement is used to estimate the reliability. Tests were split into multiple parallel parts which were used to assess the reliability from repeated measurements. In the classic test theory and generalisability theory the reliability is the proportion of variation in scores that can be contributed to true differences between the units of analysis and not to irrelevant, random effects errors or to other fixed factors. Measurements should have at least interval level, that is invariant for linear transformations.

Two types of reliability coefficients are distinguished. Relative coefficients indicate the extent to which units of analysis can be distinguished from each other. Absolute coefficients indicate the extent to which the position of the units of analysis can be estimated within the range.

\section{Model 1 Patients as units of analysis}

We assumed that both patients and questions were random samples from larger populations (random effects). No attention was paid to the fact that patients belong to a particular general practitioner so they were not nested within the general practitioner (see note). This model is used for the calculation of a generalisability coefficient which is comparable with coefficient $\alpha$.

SOURCES OF VARIATION

(1) $P$ patients

(2) I questions

(3) $P \star I, e$ interaction of patients and questions, error variation.

RELATIVE RELIABILITY COEFFICIENT

where $n_{i}$ indicates the number of items.

$$
\mathbf{P} /\left(\mathbf{P}+\left(\mathbf{P}^{\star} \mathrm{I}, \mathrm{e} / \mathbf{n}_{\mathrm{i}}\right)\right)
$$

This coefficient can be seen as the expected mean correlation between the questions in a particular dimension, that would be found if measurements were infinitely repeated with different random samples of questions in that dimension. By replacing $n_{i}$ with other values than the actual sample size, projections of reliability coefficients are obtained from different measurement conditions.

Model 2 General practitioners as units of analysis

In this model patients are nested within general practitioners. Patients and questions are regarded as random samples for larger populations (random effects).

SOURCES OF VARIATION

(1) $\mathrm{H}$ general practitioners

(2) $\mathrm{P}: \mathrm{H}$ patients nested within general practitioners

(3) I questions

(4) $I^{\star} \mathrm{H}$ interaction of questions and general practitioners

(5) $I \star P: H, e$ interaction of questions and patients nested within general practitioners, other interactions and error.

\section{RELATIVE RELIABILITY COEFFICIENT}

$$
\mathrm{H} /\left(\mathrm{H}+\left(\mathrm{P}: \mathrm{H} / \mathrm{n}_{\mathrm{p}}\right)+\left(\mathrm{I} \star \mathrm{P}: \mathrm{H}, \mathrm{e} / \mathrm{n}_{\mathrm{i}} \mathrm{n}_{\mathrm{p}}\right)\right)
$$

where $n_{i}$ indicates the number of items and $n_{p}$ the number of patients.

This coefficient is the expected mean correlation between the scores per general practitioner, if measurements were infinitely repeated with different random samples of patients and questions for that dimension.

\section{Note}

It can be argued that a nested model should be specified for the reliability per patient for a valid comparison with the reliability per general practitioner. However, estimations based on such a nested model gave similar results to model 1 (at maximum 0.01 difference in the estimation of reliability coefficients).

Questions were considered as random effects, as for each aspect of care many alternative questions can be formulated.

Box 1 Generalisability theory.

Furthermore, it is possible that reliability varies across different aspects of care that are evaluated by patients. For example, the evaluations of organisational aspects may have different reliability coefficients than the evaluations of interpersonal aspects of care. It is not known to what extent the reliability of scores per patient and the reliability of the aggregated score will differ in reality. Therefore we performed this study with real data from surveys of patients to estimate and predict the reliability of both individual and aggregated scores for different numbers of questions and patients and for different aspects of care. 
Table 1 Patients'judgements of care in general practice $(n=739)$

\begin{tabular}{llllll}
\hline & & \multicolumn{5}{l}{ Percentages * } \\
\cline { 5 - 6 } Dimensions (questions (n)) & Mean & (SD) & Poor & Fair & Good \\
\hline Organisation of appointments (9) & 4.7 & $(0.83)$ & 2.3 & 25.0 & 72.7 \\
Availability for emergencies (3) & 4.4 & $(1.25)$ & 12.9 & 25.7 & 61.4 \\
Premises (3) & 4.3 & $(1.11)$ & 10.9 & 30.5 & 58.6 \\
Continuity (4) & 4.7 & $(1.00)$ & 3.6 & 22.6 & 73.8 \\
Cooperation (4) & 4.4 & $(1.19)$ & 9.7 & 29.7 & 60.6 \\
Medical care (6) & 4.6 & $(0.99)$ & 3.6 & 28.2 & 68.2 \\
Relation and communication (10) & 4.7 & $(0.98)$ & 3.4 & 26.8 & 69.8 \\
Information and advice (6) & 4.6 & $(1.01)$ & 3.2 & 28.9 & 67.9 \\
Support (6) & 4.3 & $(1.26)$ & 11.8 & 30.0 & 58.2 \\
\hline
\end{tabular}

* Scores for the dimensions, expressed on the six point scale, were collapsed into three categories: $1-2.49=$ poor; $2.5-4.5=$ fair; $4.51-6=$ good.

\section{Methods}

SUBJECTS AND DATA COLLECTION PROCEDURES Twenty eight general practitioners from different areas in The Netherlands performed a survey among chronically ill patients in their practices. The study population consisted of patients with one or more of the following diseases: chronic obstructive pulmonary disease or asthma, diabetes mellitus, chronic diseases of the locomotor system, cardiovascular diseases, and migraine. As an earlier study had shown that there were few differences between handing out questionnaires to consecutive patients and posting questionnaires to a sample from the patients' register, ${ }^{5}$ the choice could be made by the general practitioners. Most general practitioners (25) handed out a written questionnaire to 50 patients who consecutively visited the practice. The remaining three general practitioners took a systematic sample of 60 patients from the computerised patient register and posted a questionnaire after the list of names was checked by the general practitioner for sampling errors and for important medical or social contraindications (severe illness, psychiatric distress). The sample was representative of those who went to the general practitioner.

A total of 1210 questionnaires were actually given or sent to the patients. Patients completed the questionnaire at home and sent it to the Department of General Practice and Social Medicine of the University of Nijmegen. The general practitioners received a report including a summary of the results in their practice.

\section{VARIABLES AND MEASUREMENT}

Patients' judgements of care in general practice were measured by a previously validated questionnaire for chronically ill patients to evaluate care in general practice. This questionnaire was based on a consensus study with a panel of practitioners and patients ${ }^{6}$ and on studies with surveys of 920 patients in 14 general practices. $^{7}$

\footnotetext{
1430 Questionnaires were delivered to 28 general practitioners

180 Were posted to patients

1210 Were handed out to patients

40 Were not given out by the general practitioner

762 Questionnaires were received at the university (referring to 28 general practitioners)

739 Questionnaires were selected out of these 762 as they had at least 15 questionnaires per general practitioner (leaving 23 general practitoners)

345 Questionnaires were selected out of these 739 to achieve equal numbers per general practitioner (a random selection was made for each general practitioner); for some aspects of care a lower number of patients was selected
}

The questionnaire focuses on several aspects of care, organised in nine dimensions that were found in statistical clustering (unpublished data). Most questions contained a six point answering scale ranging from poor, doubtful, fair, moderately good, good, to very good. For some aspects questions with a different answering scale were used as well, but these questions are not used in this study.

\section{ANALYSIS}

For the estimation of reliability coefficients we used the generalisability theory, which is an extension of the classic test theory. ${ }^{8-10}$ In a survey of patients this approach implies an analysis of the variation in patients' answers across different patients and different questions. The total variation is divided into different components. One such compononent is true variation: the variation which can be contributed to differences between the objects of measurements (units of analysis). Another component is error variation, which is the variation that cannot be explained by any of the factors studied. The proportion of true variation relative to the total variation, a figure between 0 and 1 , is the reliability coefficient. In this study we consider a reliability coefficient of 0.95 as very good, 0.80 as good, and 0.70 as acceptable. As the number of relevant measurements increases, the reliability coefficient is higher. Reliability coefficients can be estimated for different hypothetical numbers of patients and questions, with real data used for the projections. In these decision studies different sources of variation and their relations can be specified.

\section{PATIENT SAMPLE}

For the analysis we used the computer program GENOVA, ${ }^{11}$ which requires a balanced data set (equal number of patients per general practitioner). The number of patients was very small for some general practitioners. Therefore the 23 general practitioners were selected for whom judgements of at least 15 patients were available. If more than 15 patients were available, a random sample of 15 was drawn. In this way a data set of 345 patients from 23 general practitioners was extracted. For the dimensions availability for emergencies and support less than 15 patients were available for some general practitioners. For these dimensions the estimations had to be based on eight and 14 patients, respectively, per general practitioner. For all analyses the original scores, expressed on the six point answering scale, were used.

\section{RELIABILITY PER PATIENT}

Next, for each dimension two approaches were taken in the estimation of reliability coefficients. In the first approach three compononents were distinguished in the variation of patients' judgements of care: $(a)$ differences between patients, (b) differences between questions, $(c)$ differences between a combination of patients and questions, and $(d)$ error variation (which cannot be distinguished from the patient by question interaction term 
Table 2 Estimated reliablilty coefficients for scores per patient for different numbers of questions (simulation study)

\begin{tabular}{llllll}
\hline & \multicolumn{2}{l}{ Questions $(n)$} & & & \\
\cline { 2 - 7 } & 1 & 3 & 5 & 7 & 9 \\
\hline Organisation of appointments & 0.48 & 0.73 & 0.82 & 0.87 & 0.89 \\
Availability for emergencies & 0.74 & 0.90 & 0.94 & 0.95 & 0.96 \\
Premises & 0.43 & 0.69 & 0.79 & 0.84 & 0.87 \\
Continuity & 0.61 & 0.82 & 0.89 & 0.92 & 0.96 \\
Cooperation $\dagger$ & 0.70 & 0.87 & 0.92 & 0.94 & 0.95 \\
Medical care & 0.74 & 0.89 & 0.93 & 0.95 & 0.96 \\
Relation and communication & 0.64 & 0.84 & 0.90 & 0.93 & 0.94 \\
Information and advice & 0.71 & 0.88 & 0.92 & 0.94 & 0.96 \\
Supportł & 0.83 & 0.94 & 0.96 & 0.97 & 0.98
\end{tabular}

Projections were based on 15 patients per general practitioner except for ${ }^{\star}$ based on sample of 8 per general practitioner; $\nmid$ based on sample of 12 per general practitioner; $\ddagger$ based on sample of 14 per general practitioner.

for technical reasons). The reliability coefficient is the ratio between $(a)$ and $(a)$ and $(c)$ in which $(c)$ is divided by the sample size of the questions of interest (box 1 for formulae). As the differences between questions $(b)$ was not included, only relative differences between patients are referred to. The resulting coefficients are therefore comparable with the coefficient $\alpha$.

RELIABILITY PER GENERAL PRACTITIONER

In the second approach the reliability of aggregated scores is estimated-that is, scores that are aggregated per general practitioner. In this approach it is acknowledged that patients belong to a specific general practitioner: they are nested within a general practitioner. The following compononents were distinguished in the variation: (a) differences between general practitioners, $(b)$ differences between patients

Table 3 Estimated reliability coefficients of scores per general practitioner for different numbers of questions and patients (simulation study)

\begin{tabular}{|c|c|c|c|c|c|c|}
\hline & \multirow[b]{2}{*}{ Patients (n) } & \multicolumn{5}{|c|}{ Questions (n) } \\
\hline & & 1 & 3 & 5 & 7 & 9 \\
\hline Organisation of appointments & $\begin{array}{l}30 \\
60 \\
90\end{array}$ & $\begin{array}{l}0.50 \\
0.57 \\
0.60\end{array}$ & $\begin{array}{l}0.69 \\
0.75 \\
0.78\end{array}$ & $\begin{array}{l}0.72 \\
0.80 \\
0.84\end{array}$ & $\begin{array}{l}0.74 \\
0.83 \\
0.86\end{array}$ & $\begin{array}{l}0.76 \\
0.84 \\
0.87\end{array}$ \\
\hline Availability for emergencies & $\begin{array}{l}30 \\
60 \\
90\end{array}$ & $\begin{array}{l}0.36 \\
0.48 \\
0.53\end{array}$ & $\begin{array}{l}0.45 \\
0.59 \\
0.66\end{array}$ & $\begin{array}{l}0.47 \\
0.62 \\
0.70\end{array}$ & $\begin{array}{l}0.48 \\
0.63 \\
0.71\end{array}$ & $\begin{array}{l}0.48 \\
0.64 \\
0.72\end{array}$ \\
\hline Premises & $\begin{array}{l}30 \\
60 \\
90\end{array}$ & $\begin{array}{l}0.34 \\
0.39 \\
0.40\end{array}$ & $\begin{array}{l}0.55 \\
0.62 \\
0.64\end{array}$ & $\begin{array}{l}0.62 \\
0.70 \\
0.73\end{array}$ & $\begin{array}{l}0.66 \\
0.74 \\
0.77\end{array}$ & $\begin{array}{l}0.69 \\
0.77 \\
0.80\end{array}$ \\
\hline Continuity & $\begin{array}{l}30 \\
60 \\
90\end{array}$ & $\begin{array}{l}0.45 \\
0.57 \\
0.63\end{array}$ & $\begin{array}{l}0.56 \\
0.70 \\
0.76\end{array}$ & $\begin{array}{l}0.59 \\
0.73 \\
0.79\end{array}$ & $\begin{array}{l}0.61 \\
0.74 \\
0.81\end{array}$ & $\begin{array}{l}0.61 \\
0.75 \\
0.81\end{array}$ \\
\hline Cooperation $\dagger$ & $\begin{array}{l}30 \\
60 \\
90\end{array}$ & $\begin{array}{l}0.63 \\
0.75 \\
0.80\end{array}$ & $\begin{array}{l}0.70 \\
0.82 \\
0.86\end{array}$ & $\begin{array}{l}0.72 \\
0.83 \\
0.88\end{array}$ & $\begin{array}{l}0.73 \\
0.83 \\
0.88\end{array}$ & $\begin{array}{l}0.73 \\
0.84 \\
0.88\end{array}$ \\
\hline Medical care & $\begin{array}{l}30 \\
60 \\
90\end{array}$ & $\begin{array}{l}0.71 \\
0.83 \\
0.88\end{array}$ & $\begin{array}{l}0.75 \\
0.86 \\
0.90\end{array}$ & $\begin{array}{l}0.76 \\
0.86 \\
0.90\end{array}$ & $\begin{array}{l}0.76 \\
0.87 \\
0.91\end{array}$ & $\begin{array}{l}0.77 \\
0.87 \\
0.91\end{array}$ \\
\hline Relation and communication & $\begin{array}{l}30 \\
60 \\
90\end{array}$ & $\begin{array}{l}0.60 \\
0.71 \\
0.75\end{array}$ & $\begin{array}{l}0.70 \\
0.81 \\
0.85\end{array}$ & $\begin{array}{l}0.73 \\
0.83 \\
0.87\end{array}$ & $\begin{array}{l}0.74 \\
0.84 \\
0.88\end{array}$ & $\begin{array}{l}0.74 \\
0.85 \\
0.89\end{array}$ \\
\hline Information and advice & $\begin{array}{l}30 \\
60 \\
90\end{array}$ & $\begin{array}{l}0.73 \\
0.84 \\
0.89\end{array}$ & $\begin{array}{l}0.77 \\
0.87 \\
0.91\end{array}$ & $\begin{array}{l}0.78 \\
0.88 \\
0.92\end{array}$ & $\begin{array}{l}0.79 \\
0.88 \\
0.92\end{array}$ & $\begin{array}{l}0.79 \\
0.88 \\
0.92\end{array}$ \\
\hline Support & $\begin{array}{l}30 \\
60 \\
90\end{array}$ & $\begin{array}{l}0.61 \\
0.75 \\
0.80\end{array}$ & $\begin{array}{l}0.65 \\
0.78 \\
0.84\end{array}$ & $\begin{array}{l}0.66 \\
0.79 \\
0.85\end{array}$ & $\begin{array}{l}0.66 \\
0.79 \\
0.85\end{array}$ & $\begin{array}{l}0.66 \\
0.80 \\
0.85\end{array}$ \\
\hline
\end{tabular}

Projections were based on 15 patients per general practitioner except for ${ }^{\star}$ based on sample of 8 per general practitioner; $\nmid$ based on sample of 12 per general practitoner; $\ddagger$ based on sample of 14 per general practitoner. who are nested within general practitioners, $(c)$ differences between questions, $(d)$ differences between the combination of general practitioners and questions, $(e)$ differences between remaining combinations and error variation. The reliability coefficient of the aggregated score is the ratio of $(a)$ and $(a),(b),(d)$, and (e) with these components divided by the sample size of questions and patients when appropriate (box 1). As the systematic differences between questions were excluded, the coefficient refers to relative differences between general practitioners.

\section{Results}

PATIENT SAMPLE

The total sample included 762 patients (response rate of $63 \%$ ). After excluding the general practitioners with too few patients, there were 739 patients from 23 general practitioners. Of these patients $59 \%$ were women and the mean age was 62 (SD 15.2) years; $52 \%$ were 65 or older and only $10 \%$ were younger than 40. The most usual chronic diseases reported were hypertension ( $44 \%$ ), arthrosis of knee, hip, or hand (33\%), asthma or chronic obstructive pulmonary disease $(19 \%)$, and diabetes mellitus (15\%). On average the general practitioner was seen 2.4 times in the past two months. Most patients' judgements of the care in general practice were evaluated as positive (table 1). From these 739 patients a selection was made for the analyses (box 2).

RELIABILITY PER PATIENT

Table 2 shows the reliability coefficients of the scores per patient that were estimated. If only one question was used, the reliability was acceptable for five out of the nine dimensions: availability for emergencies, cooperation, medical care, information and advice, and support. The reliability was good for many dimensions if three questions were used. The exceptions were organisation of appointments and premises, where five questions were needed. There was a very good reliability in five out of the nine dimensions if nine questions were used.

RELIABILITY PER GENERAL PRACTITIONER

Table 3 shows the reliability coefficients of the scores per general practitioner. In general the reliability per general practitioner was lower, especially for smaller samples of patients. For example, for availability for emergencies the reliability was 0.90 per patient and 0.45 per general practitioner if three questions and 30 patients were used. If one question and 30 patients were used, the reliability was only acceptable for the dimensions medical care and information and advice. If three questions and 30 patients were used, the reliability per general practitioner was also acceptable for cooperation as well as relation and communication. The remaining five dimensions had coefficients below 0.70 (organisation of appointments had a coefficient of 0.69 (box 3)).

The general trend was that increases in the number of questions did not affect the reliability per general practitioner very much, whereas 
increases in the number of patients had stronger effects. If three questions and 60 patients were used, the reliability per general practitioner was acceptable for all dimensions except availability for emergencies and premises. For a reliability of 0.70 both dimensions required five questions and availability for emergencies required 90 respondents.

The number of questions and patients needed for good reliability differs between the dimensions. For medical care and information and advice only three questions and 60 patients were needed. A choice can be made between three questions and 90 patients, or five questions and 60 patients for the dimensions organisations of appointments, cooperation, relation and communication, and support (for some of these combinations the coefficients were 0.78 or 0.79 ). For the remaining dimensions even higher numbers were required for good reliability. For premises nine questions and 90 patients were needed, whereas for continuity seven questions and 90 patients were required. The reliability of the evaluations of the availability for emergencies remained below 0.80 , even if nine questions and 90 patients were used.

So, three questions and 90 patients or five questions and 60 patients would provide good reliability for most dimensions. Finally, a very good reliability (a coefficient of at least 0.95 ) was not achieved for any dimension within the range of number of questions and patients that were analysed.

\section{Discussion}

The results of surveys of patients' judgements of care should be reliable, but to save resources no more measurements should be made than necessary. This study provided insight into the number of questions and patients needed to achieve reliable scores. Increasing the number of questions may result in a good reliability of scores per patient, but not necessarily in a good reliability of scores per care provider. In medical audit the reliability of the scores per care provider is usually more relevant than the reliability of the scores per patient. It was estimated that a good reliability $(0.80)$ of the aggregated score per general practitioner or practice can be achieved for most dimensions if three questions and 90 patients, or five questions and 60 patients, are used. For some dimensions, especially those concerning the organisation of care, more questions and patients are needed. Box 3 shows how the number of questions affects the reliability coefficients for the dimension organisation of care.

An important feature of this study is the assumption that patients are not independent with respect of the care that they have received from their general practitioner. For this reason a model was used in which patients were nested within general practitioners. This is a phenomenon that is often found in medical audit and quality assessment, in which there are often fewer measurements (patients, charts, consultations) than conclusions (care providers, institutions). Ignoring this phenomenon can result in serious bias.

This study focused on the technical aspects of reliability calculations. The question can be raised whether it is always possible to increase the number of patients and questions to achieve more reliable scores. Sixty or 90 patients for each general practitioner or practice is quite a lot, particularly if the expected non-response $(20 \%-40 \%)$ is considered as well. In medical audit this sample size may be difficult to achieve, as the methods and procedures need to be feasible and acceptable for the care providers involved. Nevertheless, it is important to realise that the consequence of non-achievement is a lower reliability, so there is a strong need to be cautious in the interpretation of the results.

Finding more questions for a particular dimension of care (such as continuity) may be a challenge. On the one hand questions used for a particular aspect of care were seen as a random sample from all possible questions on that dimension. Differences in the content of the questions were ignored, as a factor analysis showed that all these questions refer to one particular dimension (unpublished data). On the other hand, we thought that questions should have a specific content which is different from the other questions. If questions are too similar, patients may feel patronised and care providers may find the information

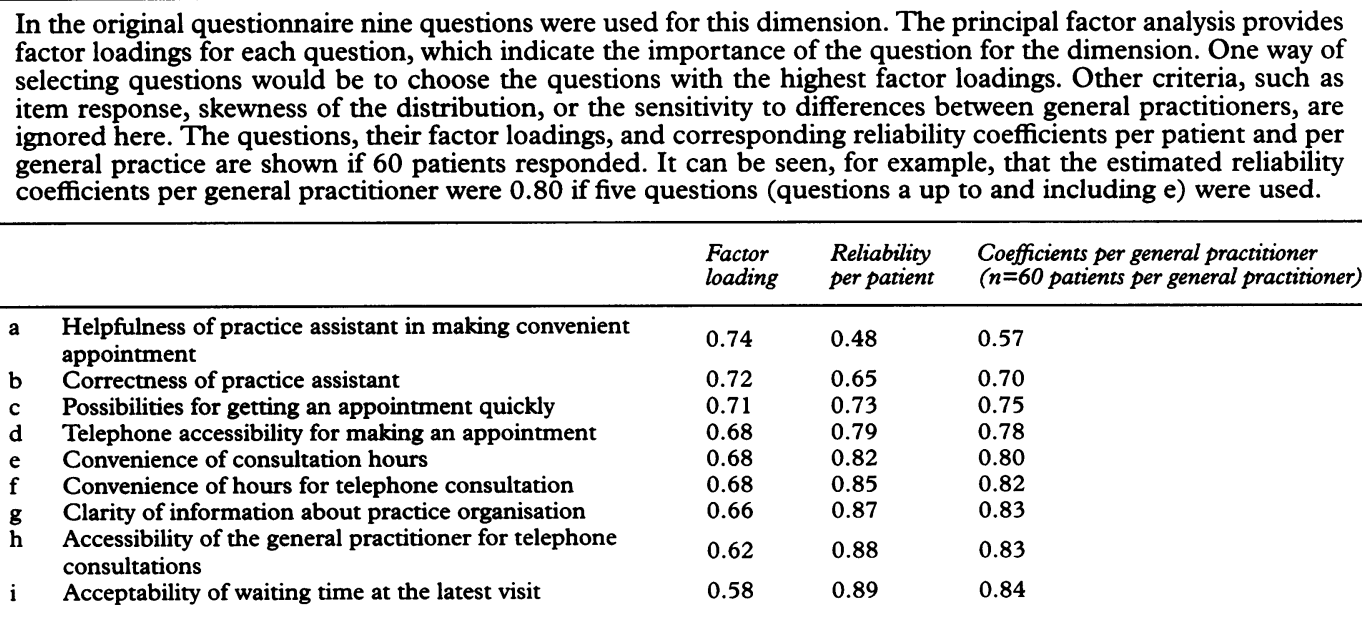


not specific enough. So the challenge was to find questions for each dimension that are different from each other, but still refer to this dimension.

This study had several limitations. The general practitioners who used the handing out procedure may have been responsible for some non-response, which could have introduced bias in the reliability coefficients per general practitioner. A specific problem is the low response rate for specific dimensions. Regression analyses (not reported) suggested that the response to each item is randomly distributed over different categories of patients, although chronically ill patients who visit the practice often tended to fill in more questions in the questionnaire. Furthermore, it is unclear whether the results can be generalised to other questionnaires for patients. For example, increasing the number of answering categories usually results in higher reliability coefficients. ${ }^{12}$

Preferably, the reliability is analysed for each questionnaire, with different approaches as shown in this article. It is important to use appropriate methodology in these situations instead of standard approaches that are common in other disciplines.
1 Kaplan SH, Ware JE. The patient's role in health care and quality assessment. In: Goldfield N, Nash DB. Providing quality. Philadelphia: American College of Physicians, 1989.

2 O'Brien RM. Estimating the reliability of aggregate-level variables based on individual-level characteristics. Sociological Methods and Research 1990;18:473-504.

3 Wensing M, Grol R, Smits A. Quality judgements by patients on general practice care: a literature review. Soc Sci Med 1994;38:45-53.

4 Swanson DB, Webster GD, Norcini JJ. Precision of patient ratings of residents' humanistic qualities: how many item and patients are enough? In: Bender W, Hiemstrab RJ, Scherpbier AJJA, Zwierstra RP, eds. Teaching and assessing clinical competence. Groningen, The Netherlands: Boekwerk Publications, 1990.

5 Wensing M, Grol R, Smits A, Van Montfort P. Evaluation of general practice care by chronically ill patients: effect of the method of administration. Fam Pract 1996;13:386-90.

6 Wensing M, Grol R, Van Montfort P, Smits A. Indicators of the quality of care of patients with chronic illness: a step towards the real involvement of patients in the assessment of the quality of care. Quality in Health Care 1996;5:73-80.

7 Wensing M, Grol R, Smits A, Van Montfort P. Hoe oordelen chronisch zieken over de huisartsenzorg? (What judgements do chronically ill patients have of general practice care?) Huisarts en Wetenschap 1996;39:402-7.

8 Brennan RL. Elements of generalizability theory. Iowa City: ACT, 1983.

9 Cronbach LJ, Gleser G, Nanda H, Rajaratnam N. The dependability of behavioral measurements: theory of generalizability for scores and profiles. New York: Wiley, 1972.

10 O'Brien RM. Generalizibility coefficients are reliability coefficients. Quality and Quantity 1995;29:421-8.

11 Crick JE, Brennan RL. Manual for GENOVA: a generalized analysis of variance system. Iowa City: The American College Testing Program, 1983. (ACT Technical Bulletin no 43.)

12 Streiner DL, Norman GR. Health measurement scales. $A$ practical guide to their development and use. 2nd ed. Oxford: Oxford University Press, 1995. 